\title{
Counterfeit/Fake and Substandard Medicines - A Global Bioethical Issue Requiring A Global Approach
}

\author{
EVANGEL SARWAR, Ph.D., MPH, HEC-C \\ evangel.sarwar@gmail.com
}

\begin{abstract}
Counterfeit drugs are a global problem and a public health hazard. Nearly 10 percent of all medicines sold worldwide are fake, leading to an estimated 100,000 deaths each year, equating to an additional economic burden of close to \$200 billion an nually. Counterfeit medicines also thwart public health efforts to control infectious diseases like Covid-19 and Tuberculosis and lead to the worsening of other public health crises such as anti-microbial resistance (AMR). According to the CDC, more than 2.8 million antibiotic-resistant infections in the U.S each year, with more than 35,000 people dying, have been reported. Globalization and the internet's expansion have led to the rapid spreading of poor-quality medicines due to the high demand for cheap goods and lack of access - before adequate detection and intervention are possible. Moreover, selling counterfeit medicine is more profitable with lesser penalties, even in the U.S. As a clandestine market, there is no precise magnitude of how the counterfeit-medicine market flows. The WHO is alarmed by the lack of available data to demonstrate the extent and impact of fake/substandard medicines. Controlling counterfeit drugs' availability will not be easy; however, it has become necessary to protect public and global health. Through the lens of a case in Bangladesh that demonstrates how easy it is to sell and get away with selling fake medicines in developing countries - this paper discusses how counterfeit medicines negatively contribute significantly to human lives and sufferings in developing and developed countries. No single policy will be effective based on the different issues faced on multiple fronts due to fake/substandard medicines. However, a broad-based concerted effort across the various stakeholders to combat this counterfeit drug problem and secure the global supply chain is urgently needed.
\end{abstract}

\section{INTRODUCTION}

Significant public health risks are associated with the global trafficking of counterfeit medicines in developing and developed countries. This illicit business, although difficult to quantify, has been estimated to be worth between $\$ 200$ billion and $\$ 431$ billion annually in total global sales. ${ }^{1}$ The World Health Organization (WHO) estimates that nearly 10 percent of all drugs sold worldwide are fake or counterfeited, with approximately 100,000 people dying each year from taking these medicines.

*Address correspondence to: Evangel Sarwar. MPH, Ph.D.,HEC-C. Department of Health Science \& Human Ecology, California State University, San Bernardino. E-mail: evangel.sarwar@gmail.com

+To cite this article: Evangel Sarwar "Counterfeit/Fake and Substandard Medicines - A Global Bioethical Issue Requiring A Global Approach. ". The Journal of Healthcare Ethics \& Administration Vol. 7, no. 1 (Winter 2021): 1-10, https://doi.org/10.22461/jhea.1.71626

This work is brought to you for free and open access by the Institute of Clinical Bioethics (ICB) at Saint Joseph's University, Philadelphia, PA, U.S.A. It has been accepted for inclusion in The Journal of Healthcare Ethics \& Administration by the editorial board and an authorized administrator of the JHEA. For more information, please contact support@jheaonline.org

\footnotetext{
${ }^{1}$ Miller, $\mathrm{H}$ and Winegarden W., "Fraud in your Pill Bottle: The Unacceptable Cost of Counterfeit Medicines," Pacific Research Institute (PRI), Center for Medical Economics and Innovation, (2020): 2.
} 


\section{THE JOURNAL OF HEALTHCARE ETHICS \& ADMINISTRATION}

Vol. 7 | No. 1 (Winter 2021)

Although this issue is more profound in developing countries due to a lack of good drug regulations or impaired or corrupted system, the issue is no longer confined within the boundaries of developing countries due to globalization and expansion of the internet through the rapid spread of poor-quality medicines worldwide before adequate detection and intervention are possible, mainly because of supplies coming from all over the world. ${ }^{2}$ Despite the gravity of this issue, data from the Pharmaceutical Security Institute that monitors the counterfeit market highlights the critical need for knowledge about the depth of counterfeit drug penetration in global legitimate medicine supply chains; there is a need for necessary data or surveillance to guide meaningful public health interventions or policy change to containing this illegal trade. ${ }^{3}$ Counterfeit medicines have become a prevalent issue everywhere and have become a challenge to public health, patient-safety and shared global health security. If left unchecked and uncontrolled, these 'dangerous medicines' will continue expansion into therapeutic and geographic scope, threatening patient lives and leading to increased antimicrobial resistance (AMR), which can lead to a worse public health crisis. ${ }^{4}$ Globalization and neoliberal policies have greatly contributed to the exacerbation of the existing injustices and progression exclusion that have negatively impacted human health and well-being, with the globalization of the pharmaceutical industry leading to the rapid spread of poor-quality medicines worldwide before adequate detection and intervention are possible, especially in resource-poor, developing countries with inadequate enforcement, lenient penalties, corruption, and ignorance of effects of fake medicines among pharmaceutical salespeople, public and health workers. ${ }^{5}$ The purpose of this paper is to look at the global scope of counterfeit medicines, elaborating on global bioethical issues of this illicit trade, with recommendations for effective global approaches to addressing this issue. The paper attempts to draw attention to the struggles developing countries such as Bangladesh face as they battle against counterfeit/substandard medicine and how this illicit trade has become an important global public health crisis that has crossed the boundaries of developing countries and has impacted developed countries such as the US and UK.

\section{ISSUES OF COUNTERFEIT MEDICINE}

While the detection of counterfeits is difficult, and the penalties are modest - with criminals relying on the continued high demand for cheap goods and lack of access - trafficking of counterfeit medicine can be extremely profitable. ${ }^{6}$ In developing countries like Bangladesh, the lack of stricter laws and punishment for counterfeit and substandard medication sales make it appealing for those involved since they have less fear of being apprehended or prosecuted than they would for other crimes. However, counterfeit medicine is now found in the legitimate pharmaceutical supply chains of the United Kingdom and the United States as well. This section looks at Bangladesh's battle with counterfeit and substandard medicines while discussing how this threat is no longer unique and has penetrated the drug supply chains in the UK and US, impacting patient-safety and public health globally.

\section{A. A case, as it affects Bangladesh}

According to Al Jazeera (2014), Hosneara lost her son, along with three other children due to the use of the same fake medicine given by doctors at the local hospital that same day. Bangladesh has seen other reported cases of mortality due to the use of fake medications - the worst outbreak in 1990-1992 - with 339 deaths reported due to the use of adulterated Paracetamol, a mild over the counter pill. Medicine can be cheap in Bangladesh because of pharmacies cutting corners and selling substandard, illegally acquired drugs, especially in poor areas. According to the Bangladesh Government, more than half a million dollars' worth of

\footnotetext{
${ }^{2}$ Bate, R and Attaran, A, "Counterfeit drugs: a growing global threat," , 376, .(2010): 1446.

3 Parks, Bea, "Pharmaceutical fakes: a dangerous pandemic," The Pharmaceutical Journal, (2015).

${ }^{4}$ Mackey, Tim and Liang, B, "Improving global health governance to combat counterfeit medicines: a proposal for a UNODC-WHO-Interpol trilateral mechanism," BMC Medicine, 11, no 233 (2013): 1.

${ }^{5}$ Newton, P et al., "Impact of poor-quality medicines in the 'developing' world," Trends in Pharmacological Sciences, 31 no3(2010): 1.

6 Jackson, G. et al., "Assessing the problem of counterfeit medications in the United Kingdom," International Journal of Clinical Practice, 66 no 3(2012): 241.
} 
counterfeit medicine were seized in raids in 2013 from Midford Market, the largest wholesale medicine hub for Bangladesh - and the ground zero of counterfeit pharmaceuticals. The Bangladesh Government is having a hard time regulating these sales. It has been estimated that there are more than 1600 unlicensed pharmacies, mostly in rural areas. Shutting these illegal dispensaries of medicine is not easy due to the lack of stricter regulations and policies. ${ }^{7}$ The issue of manufacturing and supplying of counterfeit medicines and drugs continue to grow in Bangladesh with large amount of adulterated medicine being manufactured and packaged under fake brand names, expired medicines repackaged with fake expiration dates and supplied to small local pharmacies in densely populated areas with poor people at cheap rates. The lack of knowledge about the adverse effects of various fake medicines and the cheap prices were attractive to drug store employees who sold these products for profit. ${ }^{8}$ Reputed pharmacies were not marked free from the sales of fake medicines. In July 2020, 18 people were arrested in Dhaka for manufacturing and selling counterfeit medicines in some of the well-known drug stores that sell imported medicines from the US and Canada. ${ }^{9}$ Although the drug stores were fined Tk 500,000 ( $\$ 5905.23)$ each per the Dhaka Tribune (2019), and an organization was fined Tk 300,000 ( $\$ 3543.14)$ for fake antiseptics, these are small amounts compared to the profit they make from selling these fake medicines and the cost on human life and suffering.

Poverty-stricken countries like Bangladesh have many diseases, with no access to affordable healthcare, making it impossible for many people to obtain treatment or medication. ${ }^{10}$ According to Ahmed et al. (2015), Bangladesh is experiencing rapid urban growth, with an urbanization rate of 3.5\% annually, which has increased the proportion of the population living in cities and towns from $3.6 \%$ in the 1970 s to $14.4 \%$ in $2010 .{ }^{11}$ It is estimated that $31.5 \%$ of the population still live below the national poverty line, with more poverty in rural areas. Present-day medicine, biotechnology, and healthcare powers have expressed concerns of growing vulnerability, especially in developing countries like Bangladesh, where there is not an adequate capacity for infrastructure building, which makes certain groups of the population more vulnerable than others. ${ }^{12}$ For Bangladesh, the lack of adequate enforcement against corruption, the prevalence of ignorance of the adverse effects of counterfeit medicine, and the resource-poor condition that the population lives in makes them vulnerable to exploitation and abuse of this illicit trade.

\section{B. How it affects developed countries such as the UK and US}

There is a common misperception that counterfeiting of medicines is an issue only in developing countries. At "200-billion-a-year," this industry is very profitable, and countries like the UK and the US are no longer immune to counterfeit medicines due to globalization. ${ }^{13}$ Any medication in demand by consumers provides a profit opportunity for counterfeiters, who are unconcerned about victims' health consequences. ${ }^{14}$ The globalization of health-care delivery has led to the most complex and challenging problem of securing the integrity and safety of the global medicine supply chain. ${ }^{15}$ According to the WHO, although the UK had $<1 \%$ of pharmaceutical sales of medicine, that is a considerable amount, $>8$ million packs of medicines worth approximately $£ 425$ million. ${ }^{16}$

\footnotetext{
7 "Bangladesh faces growing trade in fake drugs," Al Jazeera, YouTube (2014).

8 Hasan, Kamrul, "Detectives bust counterfeit medicine making gang in Dhaka," Dhaka tribune, (2019). Retrieved from: https://www.dhakatribune.com/bangladesh/nation/2019/02/03/detective-branch-police-busts-fake-medicine-making-gang-in-city

9 Rabbi, Arifur Rahman, "18 held for selling counterfeit medicines in Dhaka," Dhaka Tribune, (2020, July 10). Retrieved from: https://www.dhakatribune.com/bangladesh/dhaka/2020/07/10/18-held-over-counterfeit-medicines-in-dhaka

${ }^{10}$ Have, Henk ten. "Vulnerability: Challenging bioethics," London: Routledge, (2016): 7.

${ }^{11}$ Ahmed et al., "Bangladesh Health System Review," Health Systems in Transition, Asia Pacific Observatory on Public Health Systems and Policies. 5 no 3(2015): 2

${ }^{12}$ Have, Henk ten., "Vulnerability: Challenging bioethics,"pp. 8-9.

${ }^{13}$ Iris, John, "Customs group to fight $\$ 200$ bln bogus drug industry," (2010).

${ }^{14}$ Jackson, G. et.al., pp. 242.

${ }^{15}$ Mackey, Tim K. et al., "Assessing the problem of counterfeit medications in the United Kingdom. Counterfeit Drug Penetration into Global Legitimate Medicine Supply Chains: A Global Assessment," The American Society of Tropical Medicine and Hygiene. 92 no. 6 (2015): 59.

16 Jackson, G. et.al., pp. 247
} 


\section{THE JOURNAL OF HEALTHCARE ETHICS \& ADMINISTRATION}

Vol. 7 | No. 1 (Winter 2021)

Additionally, the Chinese counterfeiters' contamination of heparin in 2007 and 2008 killing 149 patients in the US alone proved that no country was safe from this threat. ${ }^{17}$

The availability of the counterfeited cancer drug, Avastin, in the US in 2012 resulted in many patients to miss their chemotherapy for some time, harming the patients. ${ }^{18}$ Despite the recognized dangers to global public health, the trade of counterfeit medicines continues to increase. Studies have indicated that nearly $40 \%$ of drugs are made overseas, and approximately $80 \%$ of the active medicinal components of drugs are imported, which makes it challenging to prevent counterfeit medicines from entering the US. ${ }^{19}$ The lower prices attract buyers, and the rise of Internet Pharmacies has also made it difficult to regulate drug safety. Detecting counterfeits is often tricky because many of these goods pass through a long and complicated distribution network, creating counterfeits opportunities to enter the legitimate supply chain. ${ }^{20}$

\section{How it affects globally}

As drug supply chains increasingly become cross-continent, the issue of counterfeit medicine has reached global proportions, with a lack of accurate understanding of the extent of the problem that makes this of utter importance to find solutions. The WHO has analyzed 100 studies from 2007-2016, covering more than 48,000 samples, of which 10.5 percent were fake or substandard in low and middle-income countries, showing a $\$ 30$ billion illicit business that generates nearly $\$ 300$ billion a year in pharmaceutical sales in these countries. Wealthier countries were not exempt from this trade, with more than 13 million doses of counterfeit medicine ranging from opioids to heart medicine seized in 2019 by Europol, the European Union's law enforcement agency that attributed the rise of these counterfeit medicines due to "the relatively low risk of criminal detection." ${ }^{21}$ Both the CDC and the WHO fears that counterfeit medications have become a global problem, with the WHO attributing the prevalence to lax rules, and because of the attractive risk-return trade-off compared to other illegal activities in developing countries, such as parts of Asia, Africa, and Latin America. ${ }^{22}$ Moreover, selling counterfeit medicine is more profitable with lesser penalties, even in the U.S. According to Blackstone et al., there is a $\$ 30$ dollar return for every dollar invested, which is even higher than the potential return from selling heroin, which is only \$3. Criminal penalties for selling heroin and other narcotics can be up to a lifetime in jail and fines in millions of dollars, versus up to three years in jail and fines up to $\$ 10,000$ for selling counterfeit prescription drugs. Given these incentives, it is not surprising that counterfeit drugs are a growing global problem. ${ }^{23}$

Antibiotics are the most counterfeited medicines and account for $28 \%$ of global counterfeit medicines. An estimated $5 \%$ of the worldwide antibiotic market is counterfeited, making it a public health hazard due to the emergence of anti-microbial resistance (AMR). ${ }^{24}$ Per Berman (2019), an anticipated 10 million people a year will die by 2050 due to the evolution of AMR. ${ }^{25}$ Unfortunately, the mortality risks extend to patients taking medications for common health issues, such as counterfeited anti-flu drug Tamiflu, weight-loss pill Alli, pneumonia and antimalarial drugs. Sold over the internet, these drugs are deadly because they lack the active ingredients and may contain ingredients that can cause severe adverse allergic reactions or side effects. According to the Organization for Economic Cooperation and Development (OECD), counterfeited pneumonia and anti-malarial drugs have been reported to cause 72,000 to 169,000 deaths in children annually. Moreover, counterfeit medicines thwart public health efforts to control infectious diseases like Covid-19 and lead to the worsening of AMRs. More than 2.8 million AMR infections have been

\footnotetext{
${ }^{17}$ ate, $R$ and Attaran, pp. 685

${ }^{18}$ Stones, Judy, "Counterfeit Drugs: a Deadly Problem,"Scientific American, (2012).

${ }^{19}$ Blackstone, Erwin A. et al., "The Health and Economic Effects of Counterfeit Drugs," American Health and Drug Benefits. 4, (2014): 217.

${ }^{20}$ Blackstone, Erwin A., pp.221.

${ }^{21}$ Miller, $\mathrm{H}$ and Winegarden W., pp. 6.

${ }^{22}$ CDC. Retrieved from: https://wwwnc.cdc.gov/travel/page/counterfeit-medicine

${ }^{23}$ Miller, $\mathrm{H}$ and Winegarden W., pp. 8.

${ }^{24}$ Delepierre, A. et al., "Update on counterfeit antibiotics worldwide" Public health risks Falsification des antibiotiques dans le monde : état des lieux et risques de Santé Publique. Médecine et maladies infectieuses. 42, (2012): 247.

${ }^{25}$ Breman, Joel G., "It's time to stop murder by counterfeit medicine," Stat News, (2019).
} 
reported in the US each year with more than 35,000 people dying according to the CDC, making it a public health crisis. ${ }^{26}$ There are large economic costs also imposed by counterfeit medicine, which are overlooked. The economy is deprived in billions of dollars due to lost potential income, lost jobs, and loss of innovation due to counterfeit medicine that could lead to potential treatments that will be either delayed or never created because of the diverted resources to illegal market - which only highlights the need for eliminating counterfeit drug problems and making it a top policy priority. ${ }^{27} \mathrm{It}$ is imperative for key opinion leaders and policymakers to facilitate necessary changes to surveillance, security, and improvements to pharmaceutical governance of domestic, regional, and international drug supply chains to prevent future Counterfeit Incidents. ${ }^{28}$

\section{ISSUES WITH GLOBALIZATION ON HEALTH GOVERNANCE}

Problems of governance has always prevailed due to economic interests over health conditions. Views have differed about the response, whether it should be biomedical or whether it should be human rights-based. This lack of commitment by states resulted in the denial of the problem and inactiveness. ${ }^{29}$ The next two sections look at the global politics of health and global health governance.

\section{A. Global politics of health}

Health is a political issue that impacts at the local, national, and global levels, with the actors from all aspects of life such as health foundations like Bill and Melinda Gates Foundation, and international organizations such as the World Health Organization, World

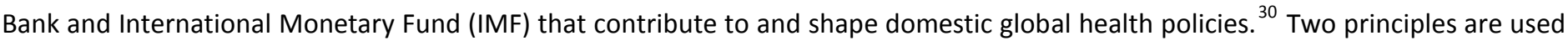
in understanding the International Politics of Health: the statist - primarily focused on public health as a means through which the state's stability can be assured, and the globalist - mainly focused on securing the well-being and rights of the individuals. Today, it has been acknowledged that social and political influences play a role in an individual's health. ${ }^{31}$

According to the statist perspective, health issues must be addressed when they directly impact the economic, political or military security of a state, and the state remains a core actor in this perspective - prioritizing the national security as a precursor to good health; but the globalist sees the state as just one among a wide number of actors, some of which have an equally significant impact on the health of individuals - maintaining the 'emphasizing securitization' can potentially divert attention away from the most deadly diseases and their causes. ${ }^{32}$ The statist perspectives make it well suited for acute crises but less well suited for chronic health crises. These may help facilitate policies to prevent particular health crises but will not alleviate the underlying causes of infectious diseases - including poverty and poor health care in developing countries. It is important to note that not all cases of poor health are the result of communicable diseases. ${ }^{33}$

Globalization has turned the issue of counterfeit medicine into a globally visible problem that has become more prevalent in developed countries as drug supply chains increasingly cross continents for cost purposes. Studies using the World Bank income division show that Counterfeit Incidents were mostly reported by upper and lower-middle-income countries. Low-income countries failed to report most incidents. This demonstrates that strong infrastructures protected the supply chains in high-income countries, whereas limited drug supply safety and counterfeits detection systems were present in low-income countries. The severity of counterfeit medicine remains undocumented - only 5-15\% of the 191 member states of the World Health Organization (WHO) report cases of counterfeit drugs, many data have been interpreted uncritically - some are inaccurate and do not allow accurate

\footnotetext{
${ }^{26}$ Miller, $\mathrm{H}$ and Winegarden W., pp.9, 10.

${ }^{27}$ Miller, $\mathrm{H}$ and Winegarden W., pp. 10, 12.

${ }^{28}$ Mackey, Tim K. et al. "Assessing the problem of counterfeit medications in the United Kingdom. Counterfeit Drug Penetration into Global Legitimate Medicine Supply Chains: A Global Assessment," pp.60.

${ }^{29}$ Have, Henk ten. Global bioethics: An introduction. (London: Routledge, 2016) pp. 150-151

${ }^{30}$ Davies, Sarah. Global Politics of Health. Cambridge, UK: Polity Press (2010): 1

${ }^{31}$ Davies, Sarah., pp. 9-10

${ }^{32}$ Davies, Sarah., op cit. pp. 14

${ }^{33}$ Davies, Sarah., pp.18-23
} 


\section{THE JOURNAL OF HEALTHCARE ETHICS \& ADMINISTRATION}

Vol. 7 | No. 1 (Winter 2021)

generalizations about the epidemiology of poor-quality medicines. The WHO received only 84 reports from member countries between 1999 and 2002, and no reports were received after 2002. Additionally, government officials of some countries have been accused of involvement in the false certification of counterfeit drugs, while other countries' governmental agencies have been criticized for suppressing information. ${ }^{34}$

There is an urgent need for policies that will alleviate the crisis initiated by the sale and procurement of counterfeit or substandard medicines, and governments need to be fully invested in finding solutions at a policy level that will discourage the supply of these products as well as curb the demand for counterfeit medicine. Strategies can involve increased punishment for selling these products and increasing enforcement efforts through improving data-and information- sharing among government departments, particularly the FDA, Customs and Border Patrol, and the United States Postal Service, that can help secure the nation's drug supply and increase the chances of intercepting counterfeit drugs. The efforts should be extended to international enforcement agencies as well, such as World Customs Organizations and so on, to foster collaboration to intercept counterfeit drugs. Implementation of track-and-trace systems to monitor unique serial numbers on the packages and reveal the product's source and distribution history through the use of technology are necessary. Additionally, educating consumers and raising their awareness about the hazards of using counterfeit medicine, and providing them with proper information about reliable internet pharmacies can greatly alleviate this issue. No single policy will be effective based on the different levels of issues faced on multiple fronts. There needs to be a concerted effort across the various stakeholders (governments, pharmaceutical companies, and distributors, as well as pharmacists and consumers), with policies addressing the different levels of this issue. ${ }^{35}$

\section{B. Issues with global health governance and counterfeit medicine}

Economic and capacity inequalities between donor states and philanthropic agencies heavily influence aid recipients' health priorities. Donor states are self-interested actors, and therefore the policy priorities they promote reflect their interests. Numerous human rights abuses are being committed in the name of protecting some form of "market" ideology, whereby we forget that many of these rights depends on people's social conditions, and market ideology determines which group will be abused or shielded. ${ }^{36}$ The increased influence of private and non-state actors on health policy and health care delivery makes it more complicated since there is no centralized authority when it comes to health governance. ${ }^{37}$ There is need for better focus on priorities and specific goals that address access to medication, protection of the vulnerable populations and ensure global justice.

Although there are many actors to help with global health funding, the WHO is still the major institution that plays a big role in international health policy, with objectives to achieve the fundamental basic right of every human being, especially health. However, collective management of global health affairs is problematic for the WHO for two reasons: First, it is centered on states as a UN agency specializing in health. Member states determine the program and its budget, which is also based on member contributions. This reduces its flexibility and capacity to set priorities. ${ }^{38}$ Second, more global health funding is provided by other institutions such as the World Bank, IMF, or wealthy private partnerships that undermine the organization's credibility and leadership. There are many actors but no director - making global health governance difficult - since many of these organizations have other interests besides health, like the World Trade Organization (WTO), which prioritizes the promotion of trade over regulation of health. As a result, the WHO lacks leadership and is not able to better manage emergencies. Because of politics, member states have cut the budget for health crises in half, with most developed countries more concerned about protecting their own interests. ${ }^{39}$

\footnotetext{
${ }^{34}$ Cockbum, R. et al. The Global Threat of Counterfeit Drugs: Why Industry and Governments Must Communicate the Dangers. Plos Medicine 2 no 4(2005): 303

${ }^{35}$ Miller, $\mathrm{H}$ and Winegarden W., pp. 13, 14.

${ }^{36}$ Farmer, Paul. Pathologies of Power: Health, Human Rights, and the New War on the Poor. Los Angeles, Berkely, London: University of California Press, (2005): 5-6.

${ }^{37}$ Davies, Sarah., pp.133.

${ }^{38}$ Have, Henk ten. Global bioethics: An introduction, pp.142-143

${ }^{39}$ Have, Henk ten., Global bioethics: An introduction, pp.144-146
} 


\section{THE JOURNAL OF HEALTHCARE ETHICS \& ADMINISTRATION}

Vol. 7 | No. 1 (Winter 2021)

Moreover, the lack of precise information about the extent of the counterfeit issue globally makes it difficult to press for enforcing mechanisms to address this issue. The data available currently cannot be compared directly since they are gathered from a variety of sources, such as national medicines regulatory authorities, different agencies that enforce regulations, pharmaceutical companies, and various studies conducted by non-governmental organizations. As scholars like Parks indicate that the problem of counterfeit medicine is underestimated and the lack of adequate surveillance system prevents the reporting of distribution and use of poor-quality medicine and is kept from the public record by governments and pharmaceutical companies, allowing this issue to thrive. $^{40}$

\section{RECOMMENDATIONS}

Globalization has created new bioethical problems that must be addressed with government mechanisms: legislation, political decision-making, professional self-regulation, public debate, expert recommendations, and practice guidelines. ${ }^{41} 1$ in 10 medical products have been reported by the WHO as being falsified or substandard in developing countries, having a significant toll on individual and public health. ${ }^{42}$ Currently, there is no authority at the global level - making national approaches inadequate. The next section looks at improving governance and how to address the issue of counterfeit medicine globally.

\section{A. Governance}

Governance of health is a daunting challenge and requires cross-border cooperation between states and between a range of different agencies and actors. It also involves the sharing of knowledge and expertise. ${ }^{43}$ It has to be acknowledged that health also depends on social and economic conditions. The difficulties and weaknesses of governance that exist today are associated with differing views of globalization. Globalization is not a process in which one global culture gets to dominate particular cultures, even though such 'globalization from above' seems to be the dominant perspective today, and these rely on the power of states since they are the only ones who can enforce laws in the absence of powerful international organizations. Strong global institutions such as the World Bank and IMF impose neoliberal policies interested in hegemonic economic forces, while Western media corporations control global information. Globalization should be 'from below' where everybody participates in globalization, involving a different approach to governance rooted in local traditions, allowing for many stakeholders' participation and grassroots movement and networks, involving global civil society and interests. ${ }^{44}$

Governance of data on medicines has been problematic, with one of the reasons being the use of inconsistent terms to describe the problem: "fake, spurious and counterfeit" are just three of the more popular. There is a need to mandate specific terms in order to avoid confusion - the term "falsified" can be considered for use by the World Health Organization (WHO) as a start. The lack of regulatory and manufacturing frameworks to police illicit trade, and little focus on countries where the majority of medicines are globally coming from, such as China and India, are also adding to the issue. Controlling this issue is more important than ever, because if this is left unchecked counterfeit medicines will destroy the progress that has been made against diseases such as malaria, HIV, and TB in developing countries as well as developed countries that did not have them due to the issue of drug resistance growing as a result of poor-quality medicines. ${ }^{45}$ Undoubtedly, globalization has added many additional layers of complexity to the supply chain that creates more opportunities for the potential (intentional) contamination/adulteration of medicine, exacerbating this problem. However, strengthening the regulatory systems for medical products as adopted by the World Health Assembly in 2014 can provide oversight and enforcement needed to improve the global supply chain integrity. Moreover, Mackey et al. (2015) emphasize the greater need for investment in enhancing the surveillance and

\footnotetext{
${ }^{40}$ Parks, Bea. , "Pharmaceutical fakes: a dangerous pandemic,"

${ }^{41}$ Have, Henk ten., Global bioethics: An introduction, pp.138

42 Breman, Joel G., "It's time to stop murder by counterfeit medicine,"

${ }^{43}$ Have, Henk ten. Global bioethics: An introduction, pp. 154

${ }^{44}$ Have, Henk ten., Global bioethics: An introduction, pp. 151-152.

45 Parks, Bea. "Pharmaceutical fakes: a dangerous pandemic,"
} 


\section{THE JOURNAL OF HEALTHCARE ETHICS \& ADMINISTRATION}

Vol. 7 | No. 1 (Winter 2021)

communication of risk information in multi-sector and multi-stakeholder strategies. ${ }^{46} \mathrm{~A}$ renewed international commitment to combat this threat is equally important to domestic-policy responses aimed at improving pharmaceutical security. In addition to increased criminal penalties for those involved in this trade as proposed by the US Counterfeit Drug Penalty Enhancement Act, drug manufacturers need to acknowledge their role in aggravating this problem due to the pricing and reduced accessibility of medicines that lead to the high market demand for counterfeit versions. ${ }^{47}$ This can be addressed by renewed pricing assessment through innovative strategies and intellectual-property management, expanding patient access and assistance programs, and out-licensing production to local manufacturers in underserved global markets. ${ }^{48}$

Donations and global funds to increase access to vaccines and other health services may not be as sustainable as initially perceived. Developing frameworks that ensure stronger, long-term health security solutions such as the International Health Regulation should be taken into consideration. Ensuring collective security and developing and strengthening core capacity in an individual country's public health through national funding should be put in place to protect individual health security. Individual countries must also be willing to ensure citizens with affordable goods and a budget to sustain their own health system. This needs national skills in economic development and price negotiation, and infrastructure capacity development through innovation and technology at the global level. ${ }^{49}$

\section{B. Better leadership from WHO with more collaboration from all}

The establishment of the WTO in 1995, and the Trade-Related Aspects of Intellectual Property Rights (TRIPS) Agreement, gradually had developing countries join them through a process of persuasion and advice, and was a deliberate and calculated move pursued by key actors, linked to the economic leverage given by trade-related factors. Global rules surrounding pharmaceutical companies resulting from TRIPS have had considerable implications for the majority of the world. ${ }^{50}$ The TRIPS agreement retains a much more robust mechanism in its Dispute Settlement Body and has had a forceful or direct influence on enforcing ever-higher IP standards in developing countries. The patent rules are making drugs unaffordable for the many developing countries' people and doing little to promote research and development of drugs for diseases that only affect the poor. ${ }^{51}$

Health equity advocates argue that the WHO and the states that house big pharmaceutical companies should pressure the pharmaceutical companies to realize their moral duty to provide the essential drugs at more reasonable prices. Besides, they argue that these governments should increase their financial aid to help low-income countries create a larger public sector budget to pay for essential medicines. ${ }^{52}$ The UN Millennium Project Task Force HIV/AIDS, Malaria, TB and Access to Essential Medicines made some good recommendations that can be helpful considerations in future policies: Medicines should be affordable, and the best way to ensure this is to progressively increase public sector budgets which will require both government and donor government's support, to reduce the costs to end-users for essential medicines and promote a transparent pharmaceutical financing mechanism that allows for the negotiation of pharmaceutical pricing based on a 'concept of equity.' The paper also advocated improvement to public health sector areas of providing health care workers transparency and equitable funding mechanisms, and medicine registration systems to monitor the use of pharmaceuticals. It seems that the root cause of the problem lies in the pharmaceutical companies' unwillingness to lower the cost and allow the production of generic equivalents. ${ }^{53}$ Generic production would go a long way to reducing the high-cost burden that the world's poor have to bear to access essential drugs - two-thirds of the developing population compared to one-fifth of the developed world pay out of pocket for crucial medicines. ${ }^{54}$ While research is a 'two-way process',

\footnotetext{
${ }^{46}$ Mackey, T. K. et al., "After counterfeit Avastin ${ }^{\circledR}$ - what have we learned and what can be done?” Nat. Rev. Clin. Oncol: (2015): 1.

${ }^{47}$ Mackey, T. K. et al., "After counterfeit Avastin ${ }^{\circledR}$ - what have we learned and what can be done?", pp - 5.

${ }^{48}$ Mackey, T. K. et al. "After counterfeit Avastin ${ }^{\circledR}$ - what have we learned and what can be done?", pp - 5-6.

${ }^{49}$ Heymann, David et al. "Global health security: the wider lessons from the west African Ebola virus disease epidemic." Lancet, 385(2015):1886.

${ }^{50}$ Robinson, Daniel F., “Confronting Biopiracy: Challenges, Cases and International Debates.” London, Washington: Earthscan, (2010):28-29.

${ }^{51}$ Robinson, Daniel F., "Confronting Biopiracy: Challenges, Cases and International Debates." pp. 32.

52 Davies, Sarah, pp.162.

${ }^{53}$ Davies, Sarah., pp.170-71.

${ }^{54}$ Davies, Sarah., pp. 163.
} 
profit-making appears to be a one-way street, with no elements of communal benefit sharing. ${ }^{55}$ TRIPS has done nothing to reduce inequity, and worse, has added additional burdens onto the world's most vulnerable and those who seek to care for them. ${ }^{56}$ Increasing the allocation and distribution of free and inexpensive medications, such as antimalarial, anti-infective, antiretroviral for key diseases, would significantly reduce the financial gains of counterfeiters, thereby preventing widespread counterfeiting of such medications. Drug quality should be monitored not just at the organizational level but throughout local and governmental levels. ${ }^{57}$

Globalization has resulted in health interdependencies. As such, we need to ensure that the global health communities respond to health security threats based on a comprehensive understanding of "prevention and remediation," as emphasized by Heymann et al. (2015). Because of globalization, there is really no border to confine diseases or health security threats; as such, health security must be treated based on global equity, solidarity, and social justice. Fake and substandard or counterfeited drugs are a threat to human and global health security, and everyone is at risk. There should be no confusion about this threat, which transcends national boundaries, raising fear and mistrust of medicines and in health systems, posing formidable challenges to health security. ${ }^{58}$ According to the WHO, the risks are overlooked because of the lack of data for the prevalence of these medicines, which are under-reported or not reported because of inadequate and strict national drug surveillance and reporting systems, with a disproportionate burden of this malice on low-income countries due to weak regulatory and criminal justice systems. ${ }^{59}$ There is a need for robust transnational agency agreements to oversee drug quality, detect fraud, and apprehend bad actors. ${ }^{60}$

\section{CONCLUSION}

Counterfeit drugs not only expose patients to potentially lethal contaminants; they also increase public health risks by failing to effectively treat contagious diseases like Covid-19 or tuberculosis, or exacerbating public health crises like the problem of AMRs. Although the severity of the medicines being counterfeited may differ, it is unconscionable when medications essential for survival are sold with no active ingredients resulting in deaths. ${ }^{61}$ Fake and substandard medicines have been attributed for the deaths of 250,000 children with common illnesses such as malaria and pneumonia in emerging countries. ${ }^{62}$ Controlling the threat of counterfeit medicine will be necessary through the cooperation and collaboration of all stakeholders involved. Bioethics must acknowledge the realities of globalization that increases disparities and the most vulnerable are those without access to necessary resources. ${ }^{63}$

\section{BIBLIOGRAPHY}

1. Ahmed, Syed Masud. et al. (2015). "Bangladesh Health System Review" Health Systems in Transition, Asia Pacific Observatory on Public Health Systems and Policies, Vol. 5 No. 3.

2. Al Jazeera. (2014). Bangladesh faces growing trade in fake drugs. YouTube, Published on Jun 23.

3. Bate, Roger and Amir Attaran. (2010). "Counterfeit drugs: a growing global threat." The Lancet 376: 685.

4. Blackstone, Erwin A. et al. (2014). "The Health and Economic Effects of Counterfeit Drugs" American Health and Drug Benefits, 4: 216-223.

5. Breman, Joel G. (2019). It's time to stop murder by counterfeit medicine. Stat News. Retrieved from: https://www.statnews.com/2019/05/07/stopping-murder-counterfeit-medicine/

6. CDC. Retrieved from: https://wwwnc.cdc.gov/travel/page/counterfeit-medicine

\footnotetext{
55 Donna Dicknson. Me Medicine vs We Medicine: Reclaiming Biotechnology for the Common Good. New York: Columbia University Press, (2013):187.

${ }^{56}$ Davies, Sarah., pp.172.

${ }^{57}$ Stones, Judy., "Counterfeit Drugs: a Deadly Problem,"

${ }^{58}$ Heymann, David et al., 1883, 1893.

${ }^{59}$ Heymann, David et al., 1893

${ }^{60}$ Heymann, David et al., 1894

${ }^{61}$ Stones, Judy., "Counterfeit Drugs: a Deadly Problem,"

${ }^{62}$ Breman, Joel G., It's time to stop murder by counterfeit medicine. Stat News, 2019.

${ }^{63}$ Have, Henk ten., Global bioethics: An introduction, pp. 208-209.
} 
7. Cockburn, R. et al. (2005). "The Global Threat of Counterfeit Drugs: Why Industry and Governments Must Communicate the Dangers." Plos Medicine, 2, 4, e100: 0302- 0308.

8. Davies, Sarah. (2010). Global Politics of Health. Cambridge, UK: Polity Press.

9. Delepierre, A. et al. (2012). "Update on counterfeit antibiotics worldwide; Public health risks: Falsification des antibiotiques dans le monde: état des lieux et risques de Santé Publique." Médecine et maladies infectieuses, 42: 247-255.

10. Dickenson, Donna.(2013). "Me Medicine vs We Medicine: Reclaiming Biotechnology for the Common Good". New York: Columbia University Press.

11. Farmer, Paul. (2005). Pathologies of Power: Health, Human Rights, and the New War on the Poor. Los Anageles, Berkely, London: University of California Press.

12. Hasan, Kamrul. (2019). Detectives bust counterfeit medicine making gang in Dhaka. Dhaka tribune. Retrieved from: https://www.dhakatribune.com/bangladesh/nation/2019/02/03/detective-branch-police-busts-fakemedicine-making-gang-in-city

13. Heymann, David L et al. (2015). Global health security: the wider lessons from the west African Ebola virus disease epidemic. Lancet, 385: 1884-901.

14. Iris, John. (2010). Customs group to fight $\$ 200$ bln bogus drug industry. Reuters. Retrieved from: https://www.reuters.com/article/us-customs-drugs/customs-group-to-fight-200-bln-bogus-drug-industryidUSTRE65961U20100610

15. Jackson, G. et al. (2012). "Assessing the problem of counterfeit medications in the United Kingdom." International Journal of Clinical Practice, 66, 3: 241-250.

16. Mackey, Tim K. and Liang, Bryan A. (2013). Improving global health governance to combat counterfeit medicines: a proposal for a UNODC-WHO-Interpol trilateral mechanism. BMC Medicine, 11(233): 1.

17. Mackey, Tim K. et al. (2015). "Counterfeit Drug Penetration into Global Legitimate Medicine Supply Chains: A Global Assessment." The American Society of Tropical Medicine and Hygiene, 92, 6: 59-67.

18. Mackey, Tim K. et al. (2015). After counterfeit Avastin ${ }^{\circledR}$ - what have we learned and what can be done? Nat. Rev. Clin. Oncol, 1-7.

19. Miller, H and Winegarden W. (2020). Fraud in your Pill Bottle: The Unacceptable Cost of Counterfeit Medicines.

20. Newton, Paul N., Green, Michael D. and Fernández, Facundo M. (2010). Impact of poor-quality medicines in the 'developing' world. Trends in Pharmacological Sciences Vol.31 No.3.

21. Parks, Bea. (2015). Pharmaceutical fakes: a dangerous pandemic. The Pharmaceutical Journal.

22. Rabbi, Arifur Rahman. (2020). "18 held for selling counterfeit medicines in Dhaka. Dhaka Tribune. Retrieved from: https://www.dhakatribune.com/bangladesh/dhaka/2020/07/10/18-held-over-counterfeit-medicinesin-dhaka

23. Robinson, Daniel F. (2010). Confronting Biopiracy: Challenges, Cases and International Debates. London, Washington: Earthscan.

24. Stones, Judy. (2012). Counterfeit Drugs: a Deadly Problem. Scientific American. Retrieved from: https://blogs.scientificamerican.com/molecules-to-medicine/counterfeit-drugs-a-deadly-problem/)

25. ten Have, Henk. (2016). Global bioethics: An introduction. London: Routledge.

26. ten Have, Henk. (2016). Vulnerability: Challenging bioethics. London: Routledge. 